\title{
THE DETERMINATION OF LEAD, CHROMIUM, ARSENIC AND SELENIUM IN SEDIMENTS AND SOIL SAMPLES BY ELECTROTHERMAL ATOMIC ABSORPTION SPECTROMETRY USING CHEMICAL MODIFIERS
}

\author{
Violeta Dediu ${ }^{1}$, Lidia Kim¹, Cristiana Cosma ${ }^{1}$, Doina Guta ${ }^{1}$ \\ ${ }^{1}$ National Research and Development Institute for Industrial Ecology - ECOIND Bucharest, \\ Drumul Podu Dambovitei St. 71- 73, 060652, Bucharest, Romania
}

\begin{abstract}
The effectiveness of some chemical matrix modifiers for the determination of lead, chromium, selenium and arsenic in sediments and soils by Zeeman electrothermal atomic absorption spectrometry have been evaluated. The addition of certain chemical modifiers decreases the volatility of the analyte element, preventing its loss during pyrolysis step while increasing the volatility of matrix components promoting a better separation also allows a higher pretreatment temperature for better separation between analyte and matrix. Pyrolysis and atomization temperatures, characteristic masses and detection limits of analytes in dissolved samples with and without modifiers have been compared. The method was validated by analysing certified reference lake sediment and soil materials.
\end{abstract}

Keywords: chemical modifiers; graphite furnace atomic absorption spectrometry, sediment, soil

\section{Introduction}

Although heavy metals are naturally occurring elements that are found throughout the earth's crust, most environmental contamination results from anthropogenic activities. The present of heavy metals in soil and sediments can be the result of local pollution or these amounts can be brought through air or water stream transportation. Nowadays, numerous analytical techniques have been developed for the determination of heavy metal contents in soil and sediment, including flame atomic absorption spectrometry (FAAS), electrothermal atomic absorption spectrometry (ETAAS), inductively coupled plasma mass spectrometry (ICP-MS) etc.

ETAAS is very often used for the determination of lead, chromium, arsenic and selenium in various samples such as sediments and soils due to its high selectivity and sensibility in analyte determination. Chemical matrix modifiers were used first time by Ediger in 1975 [1]. The role of the chemical modifier is to stabilize the analyte making higher temperatures in the pyrolysis step possible without any loss of analyte. This outcome effect is must desired in the analysis of volatile semimetals (As, Se, Te etc). Noble metals with high melting point (Pd, Pt, Ir, Rh and Ru) [2-4] and elements that can form carbides (Mo, Hf, Nb, W, Ta, $\mathrm{Zr}$ ) [5] are the most employed as mono or multi-component matrix modifiers in ETAAS technique. The most used is paladium which can be combined with magnesium nitrate or organic compounds [6-8]. Many studies have been published in the last decades about the mechanism of action of modifiers on atomization process [4]. It can be hypothesized that analyte forms nonvolatile intermetallic compounds or solid solution with palladium. Also the grafite surface is chemically involved in modifiers reactions with analyte. [9] 


\section{Materials and methods}

\subsection{Instrumentation}

The contents of lead, chromium, selenium and arsenic were determined in sediments and soil samples using a Perkin Elmer PinAAcle 900T flame and longitudinal Zeeman atomic absorption spectrometer. The spectrometer was equipped with an AS 900 autosampler. The furnace was equipped with end-capped THGA graphite tubes (transversely-heated graphite tube includes an integrated platform). Pyrolytically-coated graphite tubes with integrated L'vov platforms were used. The PinAAcle 900T spectrometer's transversely heated graphite atomizer (THGA) with Longitudinal AC Zeeman background correction provide a constant uniform temperature distribution across the entire length of the graphite tub. PerkinElmer Lumina ${ }^{\mathrm{TM}}$ single-element electrodless discharge lamps (EDL) for $\mathrm{Pb}$, As and $\mathrm{Se}$ and hallow cathode lamp (HCL) for $\mathrm{Cr}$ were used as light sources.

\subsection{Materials, reagents and solutions}

Ultra pure water $(18.0 \mathrm{M} \Omega \mathrm{cm})$ obtained from an ultrapure water system (Milli-Q Integral Water Purification System, Millipore, USA) was used throughout to prepare solutions. Analytical grade reagents of $\mathrm{HNO}_{3}(65 \%$, w/w, Chem-Lab NV), $\mathrm{HCl}(37 \%$, w/w - Sigma Aldrich) and Triton X-100 $(99.95 \%$, w/w-Merck) were used without further purifications.

The autosampler washing solution containing $\mathrm{HNO}_{3} 0.2 \%(\mathrm{v} / \mathrm{v})$ and Triton X-100 $0.1 \%(\mathrm{v} / \mathrm{v})$ was used to avoid clogging of the autosampler capillary tip, to prevent analyte adsorption of on the surface of the autosampler cups and to modify physical properties of the solution in order to improve the dispersion of sample onto the platform [5, 10-12].

A solution of $\mathrm{Mg}\left(\mathrm{NO}_{3}\right)_{2} 3 \mathrm{~g} \cdot \mathrm{L}^{-1}$ and was prepared by diluting a commercial solution of $10 \mathrm{~g} \cdot \mathrm{L}^{-1}$ $\mathrm{Mg}\left(\mathrm{NO}_{3}\right)_{2}$ from Merck and was used for $\mathrm{Cr}$ analysis.

Ultrapure ammonium dihydrogen phosphate powder (Merck) was used to prepare a $\mathrm{NH}_{4} \mathrm{H}_{2} \mathrm{PO}_{4}$ $10 \mathrm{~g} \cdot \mathrm{L}^{-1}$ working solution for the mixture of chemical modifier. A working solution of $\mathrm{NH}_{4} \mathrm{H}_{2} \mathrm{PO}_{4} 10$ $\mathrm{g} \cdot \mathrm{L}^{-1}$ and $\mathrm{Mg}\left(\mathrm{NO}_{3}\right)_{2} 0.6 \mathrm{~g} \cdot \mathrm{L}^{-1}$ was prepared as modifiers for $\mathrm{Pb}$ analysis.

The $\mathrm{Pd}(\mathrm{NO})_{3} 1 \mathrm{~g} \cdot \mathrm{L}^{-1}+\mathrm{Mg}\left(\mathrm{NO}_{3}\right)_{2} 0.6 \mathrm{~g} \cdot \mathrm{L}^{-1}$ modifier mixture was prepared from $10.0 \mathrm{~g} \cdot \mathrm{L}^{-1}$ of $\mathrm{Pd}(\mathrm{NO})_{3}$ (Merck) and $10.0 \mathrm{~g} \cdot \mathrm{L}^{-1}$ of $\mathrm{Mg}\left(\mathrm{NO}_{3}\right)_{2}$ and was used for As and Se analyses.

Analytical calibration standards $\left(1.0 \mathrm{~g} \cdot \mathrm{L}^{-1}\right)$ were prepared from stock solutions of $\mathrm{As}, \mathrm{Cd}, \mathrm{Pb}$ (Perkin Elmer) and Se (Merck) by suitable and serial dilution in $\mathrm{HNO} 30.5 \%(\mathrm{v} / \mathrm{v})$.

\subsection{Reference materials}

For the verification of analytical results obtained for the sediment samples a WQB-1 Standard Reference Material from Canada National Water Research Institute was used, and for the soil samples a Certified Reference Material ERM-CC018 from BAM Federal Institute for Materials Research and Testing. The two commercial SRMs were treated as any soil and sediment sample.

\subsection{Decomposition of samples}

The soil and sediment samples were extracted with aqua regia according to ISO 11466 under reflux conditions using a sample intake of $3 \mathrm{~g}$. The final solutions were collected in $50 \mathrm{ml}$ volumetric flasks. A blank solution was obtained in the same way using only aqua regia. 


\section{Results and discussion}

The experimental conditions for the 4 elements are given in Table 1.

Table 1 Optimized experimental conditions for ETAAS

\begin{tabular}{|l|c|c|c|c|}
\hline Element & Cr & Pb & As & Se \\
\hline Wavelength $(\mathrm{nm})$ & 357.9 & 283.3 & 193.7 & 196.0 \\
Slit $(\mathrm{nm})$ & 0.7 & 0.7 & 0.7 & 2.0 \\
Lamp current $(\mathrm{mA})$ & 25 & 350 & 260 & 200 \\
Mode & AA-BG & AA-BG & AA-BG & AA-BG \\
Measurement mode & Peak area & Peak area & Peak area & Peak area \\
Integration time $(\mathrm{s})$ & 5 & 5 & 4 & 5 \\
Sample volume $(\mu \mathrm{l})$ & 20 & 40 & 40 & 50 \\
Modifier volume $(\mu \mathrm{l})$ & 5 & 10 & 10 & 10 \\
Replicates & 3 & 3 & 3 & 3 \\
\hline
\end{tabular}

In Table 2 are presented the furnace temperature programs for the determination of analytes in sediments and soils samples. The temperature programs for the analysis were optimized to provide maximum matrix decomposition without loss of analyte.

Table 2 Furnace heating programs for the determination of $\mathrm{Cr}, \mathrm{Pb}$, As and $\mathrm{Se}$ in samples using matrix modifiers

\begin{tabular}{|ccccccc|}
\hline Element & Modifier & $\begin{array}{c}\text { Drying 1 } \\
\left({ }^{\circ} \mathrm{C}\right)\end{array}$ & $\begin{array}{c}\text { Drying 2 } \\
\left({ }^{\circ} \mathrm{C}\right)\end{array}$ & $\begin{array}{c}\text { Pyrolysis } \\
\left({ }^{\circ} \mathrm{C}\right)\end{array}$ & $\begin{array}{c}\text { Atomization } \\
\left({ }^{\circ} \mathrm{C}\right)\end{array}$ & $\begin{array}{c}\text { Cleaning } \\
\left({ }^{\circ} \mathrm{C}\right)\end{array}$ \\
\hline $\mathrm{Cr}$ & $15 \mu \mathrm{g} \mathrm{Mg}(\mathrm{NO})_{3}$ & 110 & 130 & 1500 & 2300 & 2450 \\
$\mathrm{~Pb}$ & $\begin{array}{c}10 \mu \mathrm{g} \mathrm{NH} \mathrm{H}_{2} \mathrm{PO}_{4} \\
+6 \mu \mathrm{Mg}\left(\mathrm{NO}_{3}\right.\end{array}$ & 110 & 130 & 900 & 2100 & 2400 \\
$\mathrm{As}$ & $\begin{array}{c}10 \mu \mathrm{gd}(\mathrm{NO})_{3} \\
+6 \mu \mathrm{Mg}(\mathrm{NO})_{3}\end{array}$ & 110 & 130 & 1200 & 2000 & 2450 \\
$\mathrm{Se}$ & $\begin{array}{l}10 \mu \mathrm{Pd}(\mathrm{NO})_{3} \\
+6 \mu \mathrm{Mg}(\mathrm{NO})_{3}\end{array}$ & 110 & 130 & 1300 & 1900 & 2450 \\
\hline
\end{tabular}

Significantly higher pyrolysis temperatures could be used for the majority of elements compared with those corresponding to methods without modifiers, making possible an efficient removal of concomitants prior to the atomization of analyte elements.

Each calibration curve was constructed using online auto-dilution of a working stock monoelement standard solution of $10 \mu \mathrm{g} \cdot \mathrm{L}^{-1}$ by the AS 900 autosampler. Five or ten microliters of the chemical matrix modifier was added to the blank and each standard and sample. Calibration was performed using aqueous standards in the 1 to $5 \mu \mathrm{g} \cdot \mathrm{L}^{-1}$ range. The linear curves for each analyte are presented in Figure 1. 

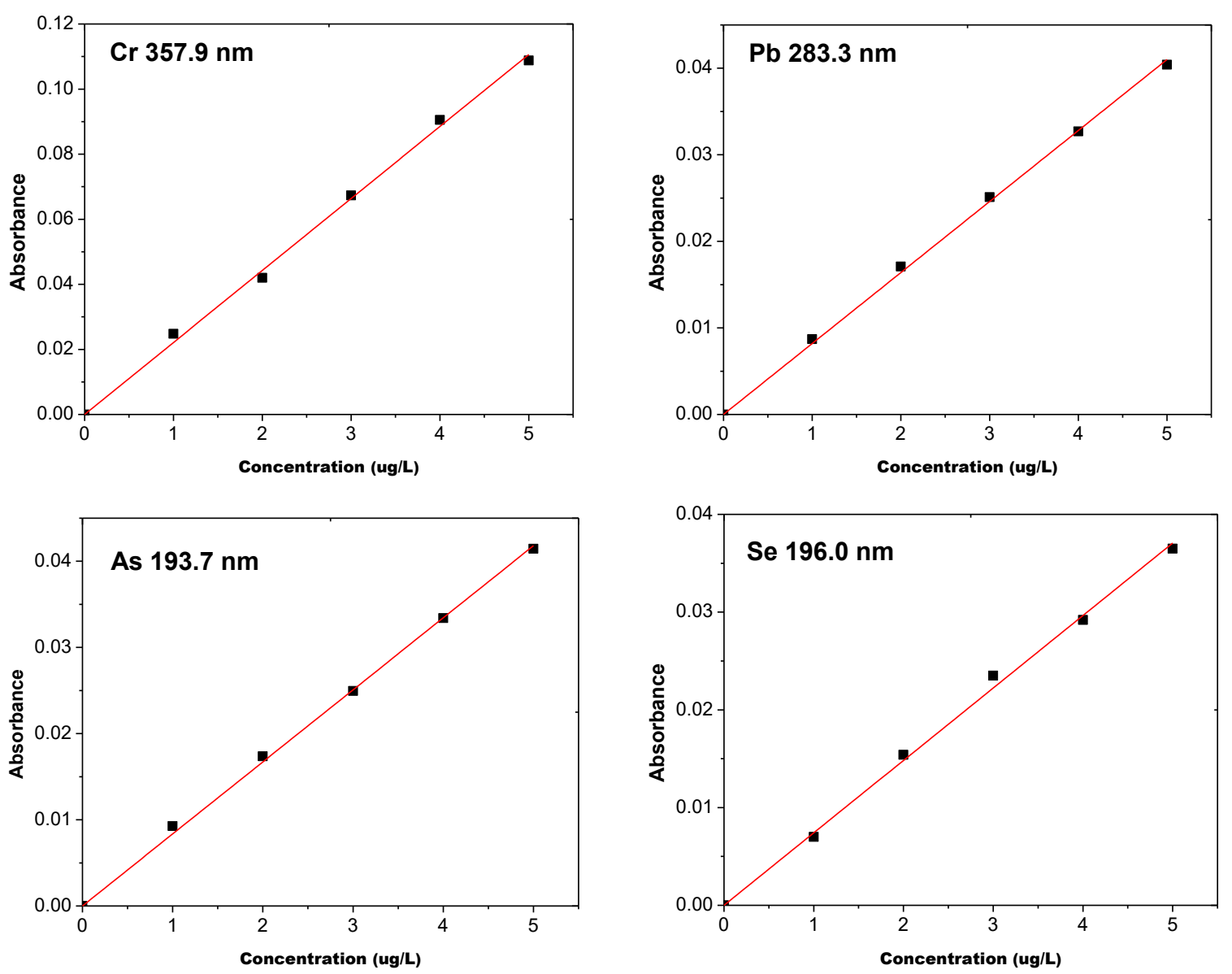

Figure 1 The linear standard curves for chromium, lead, arsenic and selenium analyses

The performance of the calibration curves was evaluated based on parameters listed in Table 3. The method for fitting was chosen to be linear through zero.

Table 3 Calibration curve parameters for chromium, lead, arsenic and selenium

\begin{tabular}{|cccc|}
\hline Element & Slope & Intercept & $\begin{array}{c}\text { Correlation } \\
\text { coeficient }\end{array}$ \\
\hline $\mathrm{Cr}$ & 0.0202 & 0 & 0.9979 \\
$\mathrm{~Pb}$ & 0.0082 & 0 & 0.9989 \\
$\mathrm{As}$ & 0.0084 & 0 & 0.9978 \\
$\mathrm{Se}$ & 0.0074 & 0 & 0.9986 \\
\hline
\end{tabular}

Calibration curves have the good correlation coefficients $\left(R^{2}>0.997\right)$ for the quantification of chromium, lead, arsenic and selenium.

The characteristic mass for the 4 elements are listed in Table 4 are in concordance with the values published in the literature when using End-capped graphite tube. 
Table 4 Characteristic Mass

\begin{tabular}{|lcccc|}
\hline Element & $\mathbf{P b}$ & $\mathbf{C r}$ & As & Se \\
\hline $\mathrm{m}_{0}(\mathrm{pg})$ & 28.7 & 4.1 & 26 & 35 \\
\hline $\mathrm{IDL}(\mathrm{pg})$ & 2.5 & 0.71 & 2.45 & 3.5 \\
\hline $\mathrm{IDL}(\mu \mathrm{g} / \mathrm{L})$ & 0.06 & 0.035 & 0.06 & 0.07 \\
\hline
\end{tabular}

In order to evaluate the accuracy of this method, the influence of the entire analytical procedure on the measured results, the content of of the arsenic, chromium, lead and selenium were measured in a certified reference sediment material (WQB-1) and a soil measured material (ERM).

Table 5 Experimental results for the ETAAS determination of metals in soil and sediment reference materials

\begin{tabular}{|c|c|c|c|c|c|}
\hline Sample & & $\mathrm{Cr}$ & $\mathbf{P b}$ & As & Se \\
\hline \multirow{3}{*}{ WQB-1 } & Found $(\mathrm{mg} / \mathrm{Kg})$ & 92.61 & 90.45 & 22.97 & 1.17 \\
\hline & Certified value $(\mathrm{mg} / \mathrm{Kg})$ & $89.1 \pm 29.4^{*}$ & $83.7 \pm 22.3$ & $23 \pm 1.84$ & $1.02 \pm 0.17$ \\
\hline & Recovery (\%) & 103.94 & 108.06 & 99.88 & 114.24 \\
\hline \multirow{3}{*}{ ERM } & Found $(\mathrm{mg} / \mathrm{Kg})$ & 129.72 & 282.14 & 22.83 & 0.56 \\
\hline & Certified value $(\mathrm{mg} / \mathrm{Kg})$ & $129 \pm 6$ & $289 \pm 10$ & $22.9 \pm 1.3$ & - \\
\hline & Recovery (\%) & 100.56 & 97.63 & 99.70 & - \\
\hline
\end{tabular}

${ }^{*}$ Non-certified element

As listed in Table 5, the founded concentrations were in good agreement with the certified values, recoveries ranged from 97.6 to 114 .

As application of the proposed methods, two sample of sediments collected from Danube River and two soil samples (at two depths $-5 \mathrm{~cm}$ and $30 \mathrm{~cm}$ ) from an industrial site were analyzed and the results (in $\mathrm{mg} / \mathrm{kg}$ ) were presented in Table 6.

Table $6 \mathrm{Cr}$, $\mathrm{Pb}$, As and Se results in environmental samples obtained following proposed methods

\begin{tabular}{|ccccc|}
\hline Sample & Cr & Pb & As & Se \\
\hline Sediment D1 & 31.56 & 19.05 & 1.34 & 0.14 \\
Sediment D2 & 56.12 & 29.01 & 7.54 & 0.17 \\
Soil 1 - 5 cm & 252.77 & 16.65 & 7.92 & 0.96 \\
Soil 1- 30 cm & 86.60 & 15.27 & 8.55 & 0.94 \\
Soil 2 - 5 cm & 98.65 & 18.15 & 7.67 & 0.50 \\
Soil 2 - 30 cm & 82.26 & 19.22 & 9.99 & 0.49 \\
\hline
\end{tabular}

The above results showed that electrothermal atomic absorption spectrometry using suitable chemical matrix modifiers can be used for accurate determination of $\mathrm{Cr}, \mathrm{Pb}$, As and Se content in environmental sample with complex matrices. 


\section{Conclusions}

In this study were presented methods for the determination of $\mathrm{Cr}, \mathrm{Pb}, \mathrm{As}$ and Se content in sediments and soil through electrothermal atomic absorption spectroscopy using chemical matrix modifiers. Good analytical characteristics such as maximum pyrolysis temperature without analyle loss, good characteristic mass and detection limits and good analyte recoveries of certified values in dissolved soil and sediment reference materials were obtained. Based on these results, the proposed methods can be applied to the determination of chromium, lead, arsenic and selenium in soils and sediments having complex matrices.

\section{References}

1. Ediger, R., Atomic absorption analysis with the graphite furnace using matrix modification. Atomic Absorption Newsletter, 1975. 14(5): p. 127-130.

2. Pereira, É.R., et al., Investigation of chemical modifiers for the direct determination of arsenic in fish oil using high-resolution continuum source graphite furnace atomic absorption spectrometry. Talanta, 2016. 150: p. 142-147.

3. Michon, J., et al., Optimization of a GFAAS method for determination of total inorganic arsenic in drinking water. Talanta, 2007. 71(1): p. 479-485.

4. Rogulsky, Y.V., V.Y. Illiashenko, and A. Kulik, Mechanism of Action of a Palladium Modifier on Atomization Processes. Journal of Applied Spectroscopy, 2014. 80(6): p. 917-921.

5. Acar, O., Molybdenum, Mo-Ir and Mo-Ru coatings as permanent chemical modifiers for the determination of cadmium and lead in sediments and soil samples by electrothermal atomic absorption spectrometry. Analytica Chimica Acta, 2005. 542(2): p. 280-286.

6. Dessuy, M.B., et al., Method development for the determination of lead in wine using electrothermal atomic absorption spectrometry comparing platform and filter furnace atomizers and different chemical modifiers. Talanta, 2008. 74(5): p. 1321-1329.

7. Pedro, J., et al., Surface studies on graphite furnace platforms covered with Pd, Rh and Ir as modifiers in graphite furnace atomic absorption spectrometry of tellurium. Spectrochimica Acta Part B: Atomic Spectroscopy, 2015. 107: p. 152-158.

8. Volynsky, A.B. and R. Wennrich, Efficiency of Pt and Ir modifiers for the simultaneous determination of As, Se and In in a sodium sulphate matrix by electrothermal atomic absorption spectrometry. Talanta, 2003. 59(2): p. 277-286.

9. Ortner, H., et al., Modifiers and coatings in graphite furnace atomic absorption spectrometrymechanisms of action (a tutorial review). Spectrochimica Acta Part B: Atomic Spectroscopy, 2002. 57(12): p. 1835-1853.

10. Acar, O., Evaluation of $V, I r, R u, V-I r, V-R u$, and $W-V$ as permanent chemical modifiers for the determination of cadmium, lead, and zinc in botanic and biological slurries by electrothermal atomic absorption spectrometry. Analytica chimica acta, 2005. 545(2): p. 244-251.

11. Lima, É.C., et al., Copper determination in biological materials by ETAAS using W-Rh permanent modifier. Talanta, 2002. 57(1): p. 177-186.

12. Lima, É.C., et al., Comparison of ultrasound-assisted extraction, slurry sampling and microwaveassisted digestion for cadmium, copper and lead determination in biological and sediment samples by electrothermal atomic absorption spectrometry. Journal of Analytical Atomic Spectrometry, 2000. 15(8): p. 995-1000. 